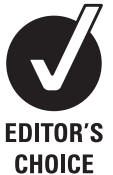

${ }^{1}$ Wales Epilepsy Research Network, Institute of Life Sciences, Swansea University, Swansea, UK ${ }^{2}$ Department of Neurology, University Hospital of Wales, Cardiff, UK ${ }^{3}$ National Public Health Service, Pontypool, UK

\section{Correspondence to}

Dr Rhys H Thomas, Wales

Epilepsy Research Network, Institute of Life Sciences,

Swansea University, Singleton Park, SA2 8PP, UK: rhys-thomas@doctors.org.uk

Received 23 April 2009

Revised 29 July 2009

Accepted 8 August 2009

\title{
Awake seizures after pure sleep-related epilepsy: a systematic review and implications for driving law
}

\author{
RH Thomas, ${ }^{1,2}$ WH King, ${ }^{3}$ JA Johnston, ${ }^{1,2}$ PEM Smith ${ }^{1,2}$
}

\section{ABSTRACT}

Who with sleep seizures is safe to drive? Driving law is controversial; ineligibility varies between individual US states and EU countries. Current UK driving law is strongly influenced by a single-centre study from 1974 where most participants were not taking antiepileptic drugs (AEDs). However, pure sleep-related epilepsy is often fully controlled on medication, and its withdrawal can provoke awake seizures.

This systematic review asked, 'What is the risk of awake seizures in pure sleep-related epilepsy?' 9885 titles were identified; 2312 were excluded (not human or adult); 40 full texts were reviewed; six papers met our inclusion criteria; each of these six studies had a different pure sleep-related epilepsy definition.

Using the largest prospective study, we were able to calculate next year's awake seizure chance (treated with antiepileptic medication). This was maximal in the second year: $5.7 \%$ (95\% Cl 3.0 to $10.4 \%$ ). European licensing bodies including the UK's Driver and Vehicle Licensing Agency broadly accept a risk of less than $20 \%$ for Group 1 licensing. However, this study excluded patients with frontal-lobe epilepsies. Furthermore, follow-up ( $n=160)$ varied from 2 to 6 years, yet new awake seizures may occur even after 10-20 years of pure sleep-related epilepsy A paucity of evidence underpins present licensing law; current rulings would be difficult to defend if legally challenged. The law may be penalising people with pure sleep-related epilepsy without increased risk of awake seizures, while failing to identify subgroups at unacceptable risk of an awake seizure at the wheel.

"I have known many persons in sleep groaning and crying out, some in a state of suffocation, some jumping up and fleeing out doors, and deprived of their reason until they awaken, and afterward becoming well and rational as before, although they be pale and weak; and this will happen not once but frequently," Hippocrates, On The Sacred Disease, circa $400 \mathrm{BCE}^{1}$

\section{INTRODUCTION \\ Sleep-related epilepsy}

The relationship between sleep and epilepsy is both intricate and complex. Seizures from sleep have been recognised for as long as we have had an appreciation of epilepsy itself. The International League Against Epilepsy (ILAE) defines sleep seizures as 'seizures occurring exclusively or predominantly (more than 90\%) from sleep.' Depending on the method of case ascertainment, this estimate has varied from 7.5 to $45 \%$ of people with epilepsy, ${ }^{2-5}$ with some estimates clustering around $12 \%$. We define pure sleep-related epilepsy as seizures occurring exclusively from sleep, including seizures that begin in sleep and continue with the patient awake.

Sleep seizures may be relatively benign-for example, the childhood partial epilepsy syndromes: benign Rolandic epilepsy (three-quarters occur from non-REM sleep, mainly at sleep onset or just before awakening) or Panayiotopoulos syndrome (twothirds arise from sleep). ${ }^{6}$ In contrast, some seizures in nocturnal frontal-lobe epilepsy (NFLE) are not only recurrent but challenging to diagnose, frequently mimicking parasomnias and having a high seizure reoccurrence rate after discontinuing AEDs. ${ }^{7}$ Pure sleep-related epilepsy may be more likely to respond to antiepileptic medication, ${ }^{8}$ but equally some people with infrequent sleep-only seizures not interfering with lifestyle do not necessarily require AEDs. However, the risk of sudden death in epilepsy is greater for those with recurrent unmedicated seizures, particularly if they sleep without a bed partner, and there are published reports of people with epilepsy dying alone in their sleep.?

\section{Driving}

Driving is a privilege enjoyed by $65 \%$ of women and $81 \%$ of men in Great Britain (2006). ${ }^{10}$ An inability or ineligibility to drive can negatively affect self esteem, reduce self sufficiency and dent employment prospects. Despite this, most countries legislate against those drivers at greatest risk of an accident when driving. Certainly any epileptic seizure could have a deleterious impact on attention, cognition and reflex response times. Uncontrolled awake seizures ensure that a driver is both unable and ineligible to drive in the UK. However, there are an unknown number of drivers with ongoing generalised seizures who are legally able to drive: they have pure sleep-related epilepsy.

The governmental body in the UK responsible for vehicle licensing is the Driver and Vehicle Licensing Agency (DVLA). They are also charged with deciding if a patient is legally able to drive. In many cases, the answer may be apparent to their clinician after consulting the DVLA guide to medical rules, named 'At a Glance.' ${ }^{11}$ Although onroad testing can assess fixed disabilities, paroxysmal disorders, such as seizures, are less well suited; the proscriptive DVLA regulations are therefore of greater importance for epilepsy. ${ }^{12}$ Medical advisory panels meet at intervals to discuss these regulations, and it is in support of this process that we have undertaken a systematic review of the literature.

\section{Accident risk}

There are a number of legal driving situations where individuals are at a higher-than-average risk of a vehicle accident. In particular, male drivers 
under the age of 25 years are perhaps at five to seven times greater risk than the mean. Schmedding ${ }^{13}$ has suggested that a relative risk ( $R R$ ) of two (a risk equivalent to legal driving after 17-19 h without sleep) may be an acceptable risk for people prone to unpredictable paroxysmal events. Using Schmedding's equation relative risk of 2.1 equates to a risk of a seizure (at any time) of $20 \%$ a year (RR of 1.5 to $10 \%$ and RR 1.1 to $5 \%$ ).

In the UK, people with pure sleep-related epilepsy may continue to drive: 'pure' means sleep only attacks for three years and 'epilepsy' is defined as at least two seizures in the past 10 years. ${ }^{11}$ Surprisingly, there is marked diversity throughout Europe in the eligibility criteria for legal driving following sleep-related epilepsy. ${ }^{14}$ Indeed, a 2004 report from the second EU working group on epilepsy and driving noted that 11 European countries had no epilepsy driving regulations at all. ${ }^{15}$ Harmonisation of EU driving regulations is under way at present; however, nations retain the ability to interpret the rulings more cautiously. ${ }^{16}$

\section{World view}

In Japan in 2002, for the first time, people with epilepsy could apply for a licence if they were seizure-free for two years: this included people with pure sleep-related epilepsy for two years' duration. ${ }^{17}$ US licensing legislation varies between states. Krauss et al noted that Utah permitted driving after three years of pure sleep-related epilepsy, and 15 states considered 'nocturnal' seizures as a mitigating factor when considering ineligibility. ${ }^{18} \mathrm{It}$ is presumed (but difficult to ascertain) that here the word 'nocturnal' is being clumsily used to be synonymous with sleeprelated seizures. In Australia, the 12-month ineligibility for people with sleep-related seizures was scrutinised in the courts. ${ }^{19}$ Beran and Devereux's discussion of a case where someone with pure sleep-related epilepsy failed to disclose that he had epilepsy to the licensing authorities also includes a detailed description of a vehicle accident occurring following a generalised seizure at the wheel, 10 years after his last reported awake seizure.

The UK requires a 36-month period of pure sleep-related epilepsy before driving can resume. In contrast, the observation period is 24 months in Belgium and Republic of Ireland, but 60 months in some cases in Sweden. ${ }^{15}$ Belgian law ${ }^{13}$ in 2002 recommended daytime driving only. Perhaps this represents a semantic error, confusing nocturnal and sleep-related seizures. Attempts at reducing the risk of an accident for higher-risk groups (driving fewer miles, avoiding motorway journeys or not attempting right turns across traffic) have thus far been avoided by legislators. In 2004, after a review of the available published evidence, the working group recommended that a period of pure sleep-related epilepsy of 12 months may be sufficient before driving resumes. Since 2004, there have been a number of valuable papers published: we aim to update this recommendation by systematically reviewing the data.

\section{Objectives and question}

We set out to identify the risk of awake seizures in patients with a diagnosis of pure sleep-related seizures. We identified and considered two subcategories: seizures treated with AEDs and seizures with onset that was generalised, focal or undetermined. We endeavoured to ascertain if the risk were static or whether it decreased for each year after diagnosis. We then wanted to compare the actual risk with that accepted by the DVLA to determine the implications for driving regulations.

\section{METHODS}

Two reviewers (RHT and JAJ) independently searched MEDLINE (1950 to February 2009), EMBASE and PsychINFO (1806 to
February 2009), Web of Science and PUBMED using a comprehensive search strategy. No language restrictions were imposed. We identified pertinent studies by searching under the terms sleep epilep*, pure sleep epilep*, wake seizure*, diurnal epilep*, driving epilep*, nocturnal epilep*, nocturnal seizure*, sleep seizure*, transform* and sleep epilep*, driv* and sleep epilep*. Studies included in the review were randomised controlled trials, case control and observational cohorts. Studies focusing only on children or animals were excluded (figure 1).

RHT and JAJ independently read all the abstracts from the citations yielded by the combined search strategy. Any disagreements were resolved by mutual discussion. We crossreferenced the identified publications by hand searching, and with SCOPUS we identified articles which cited the original retrieved studies. We also contacted authors of these key papers for any ongoing or previously unpublished data (seven contacted; five replied). ${ }^{3} 720-22$

For each of the identified studies, RHT and WHK assessed the methodological quality of each study, the numbers of participants excluded from the reported analyses or lost to follow-up, the duration of the study and the follow-up period. Particular care was taken to understand the case selection and entry criteria. Participant demographic characteristics were recorded such as age and sex and the numbers allocated to each study group. Definitions of pure sleep-related epilepsy and how such a diagnosis was confirmed, seizure types, the underlying aetiology of the seizure disorder and the presence of any comorbidities such as learning disability were noted.

\section{Outcomes}

Having identified the methodological quality of each study, data relevant to determining the annual risk of conversion to awake seizures were extracted from each study. This included information on the total numbers of patients studied, the number of patients censored and the number of patients converting to awake seizures. Where this information is not clearly available from the study, the authors were contacted, and the relevant information was requested. In studies where it was possible to obtain this information, annual risks of conversion to awake

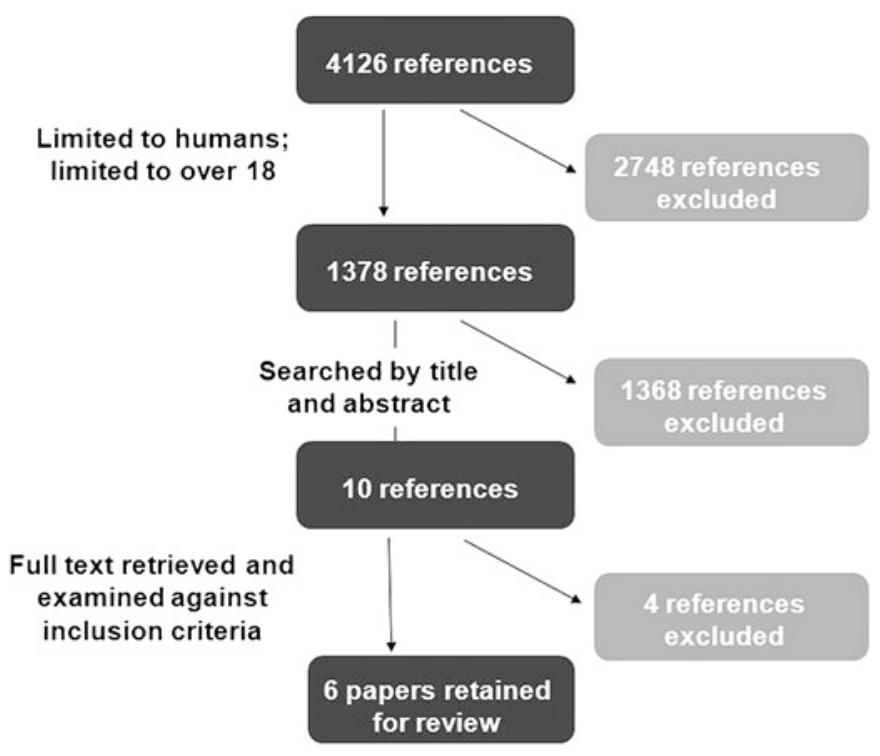

Figure 1 Search strategy: process of identifying articles from PubMed. A similar process was undertaken for each of the other medical databases. 
seizures were calculated, with censoring corrected for using the actuarial method. ${ }^{23}$ Confidence intervals for these risks were calculated using the method of Wilson. ${ }^{24}$ The study design of two key papers ${ }^{72}$ prevented us from calculating these rates. We also identified: whether the patients developed a generalised or focal seizure disorder (and how this was ascertained); whether patients were taking AEDs at entry to the study and during the observation period; the response to medication; and the people with epilepsy excluded from the study.

\section{RESULTS}

\section{Included studies}

The search strategy yielded 9885 papers (table 1), many of which were duplicates. Five key papers were identified for systematic review; the sixth was Provini et al's ${ }^{25}$ paper, which did not meet our criteria but provided useful information on the topic. Table 2 summarises the characteristics of the papers.

\section{Description of included papers}

Gibberd and Bateson's ${ }^{3}$ retrospective study of patients at a single UK centre identified 76 people with pure sleep-related epilepsy, of whom 23 developed new awake seizures over a remarkably variable study period of $1-42$ years. D'Alessandro et al's ${ }^{20}$ paper from 1983 was more a description of outcomes from their practice than a robust study and was not considered further. Park et $a^{\prime} s^{21}$ retrospective single centre study identified 63 people with pure sleep-related epilepsy and 12 of whom developed awake seizures within the 2 years of study. Provini et al's ${ }^{25}$ retrospective review of 'nocturnal' frontal-lobe epilepsy was performed at a tertiary centre in Italy solely including people referred for polysomnography. Between 1972 and 1995, 100 manifested nocturnal attacks during the recordings, which were performed after medication had been withdrawn. They reported that $34 \%$ of patients had 'occasional' awake seizures, $8 \%(8 / 34)$ developing new awake seizures after first developing pure sleeprelated epilepsy.

D'Alessandro et al ${ }^{22}$ published a multicentre study of 161 consecutive people with a new diagnosis of epilepsy and sleeponly seizures. Treatment was pragmatic with each centre allowed to treat as usual practice: $93 \%$ were given AEDs, and $78 \%$ achieved total seizure freedom at 2 years. Fernández and SalasPuig's ${ }^{7} 10$-year retrospective study of 55 people with pure sleeprelated epilepsy, 17 of whom developed awake seizures, is the most recently published. For inclusion, the patients needed to have had at least three sleep-related seizures over a period of 10 years or more. The mean age of seizure onset was 25.2 years; the average age of participants was 52.6 years.

\section{Estimates of awake seizure rate}

We were able to calculate the year-on-year risk of an awake seizure from two papers. The maximum estimated chance of seizure in the next year in Gibberd and Bateson's ${ }^{3}$ paper was $15 \%(95 \%$ CI (8.2 to $26.5 \%))$ and for D'Alessandro et al's study $2004,{ }^{22} 5.7 \%$ (95\% CI 3.0 to $10.4 \%$ ).

\section{Focal versus generalised epilepsies}

Each study attempted to distinguish between focal and generalised epilepsies using EEG criteria and sometimes an eye witness. However, there was shared speculation that focal onset seizures would be poorly described by a bed partner. Park et al's ${ }^{21}$ paper identified a discrepancy between focal and generalised epilepsies. Eleven out of 42 (26\%) developed awake seizures in the partial-onset group, and the single individual in the generalisedonset epilepsy $(1 / 21,5 \%)$ experienced a likely focal event. It is important to state that the people with pure sleep-related epilepsy were not newly diagnosed and indeed had epilepsy for an average of 8 years before inclusion in the study. This lag-time between diagnosis and inclusion exhibited great variability, and so it is difficult to draw conclusions about time to awake seizures following diagnosis with pure sleep-related epilepsy.

Multivariate analysis of D'Alessandro et al's data ${ }^{22}$ suggested that high initial seizure frequency and sudden AED withdrawal were associated with increased risk of awake seizures. Although intuitively correct, we must be cautious in relying on post hoc analysis of such small samples-for example, only two people had both risk factors. There is a striking predominance of generalised-onset seizures in both the sample group as a whole $(85 \%)$ and in the proportion that developed awake seizures $(n=18,83 \%)$. If real, this distribution may have resulted from the decision to exclude frontal-lobe epilepsies. However, the decision to differentiate between focal and generalised epilepsies using primarily EEG criteria may have skewed the data: 47/161 had diagnostic EEGs, 31 showing a focal abnormality. This low pickup can be partially explained by the high prevalence of participants on AEDs at entry to the study.

\section{Response to treatment}

The year-by-year risk of developing awake seizures (after the second year peak) for Gibberd and Bateson's paper ${ }^{3}$ (figure 2) seems to support the UK 3-year rule (implemented 3 years earlier), However, the pharmacological options available to a 21st-century epileptologist are greater, and it is now much more common for people with pure sleep-related epilepsy to receive antiepileptic therapy. It is unclear as to how many patients were treated, but the last paragraph suggests it was not many '.... a few sleep attacks do not themselves justify therapy. Until a proper trial is published the physician must be alive to the possibility of worsening the patient's seizures with his medication.' This may explain why so few of the study group attained seizure freedom (23/73 within 15 years and 15 at 3 years) in stark contrast with later studies. Yaqub et al's ${ }^{8}$ consecutive cases of sleep-related epilepsy in Saudi patients achieved 94\% seizure

Table 1 Source of papers identified for inclusion

\begin{tabular}{llllllll}
\hline & Retrieved & $\begin{array}{l}\text { Excluded: animals } \\
\text { or under } \mathbf{1 8}\end{array}$ & $\begin{array}{l}\text { Excluded at } \\
\text { abstract }\end{array}$ & $\begin{array}{l}\text { Full text } \\
\text { retrieved }\end{array}$ & Duplicates & $\begin{array}{l}\text { Excluded after } \\
\text { full text }\end{array}$ & Included \\
\hline PUBMED & 4126 & 1378 & 1368 & 10 & 0 & 6 & 4 \\
Web of Science & 5403 & 902 & 883 & 19 & 10 & 7 & 2 \\
EMBASE & 117 & 32 & 27 & 5 & 4 & 1 & 0 \\
PSychINF0 & 239 & 37 & 35 & 2 & 1 & 1 & 0 \\
MEDLINE & 247 & 100 & 96 & 4 & 3 & 1 & 0 \\
Total & & & 2278 & 40 & 18 & 16 & 6 \\
\hline
\end{tabular}


Table 2 Characteristics of studies that met inclusion criteria

\begin{tabular}{|c|c|c|c|c|c|}
\hline & Study size and period & $\begin{array}{l}\text { Minimum sleep } \\
\text { seizures }\end{array}$ & Location and design & Antiepileptic therapy & Excluded \\
\hline Gibberd and Bateson ${ }^{3}$ & $\begin{array}{l}\text { 6-year retrospective; } \\
\text { follow-up of one to } \\
42 \text { years; sample } \\
\text { size-645; } 76 \text { with sleep } \\
\text { seizures }\end{array}$ & $\begin{array}{l}\text { One seizure, clinical } \\
\text { epilepsy diagnosis and } \\
\text { an EEG; pure sleep } \\
\text { epilepsy for } 6 \text { months } \\
\text { following first seizure; } \\
\text { motor seizures only }\end{array}$ & $\begin{array}{l}\text { Retrospective cohort of } \\
\text { outpatients; single UK } \\
\text { centre }\end{array}$ & $\begin{array}{l}\text { Unclear; most probably } \\
\text { untreated }\end{array}$ & $\begin{array}{l}17 \% \text { of case notes were } \\
\text { unavailable }\end{array}$ \\
\hline $\mathrm{D}^{\prime}$ Alessandro et $\left.a\right|^{20}$ & Unclear & 2 or more & $\begin{array}{l}\text { Retrospective cohort of } \\
\text { outpatients; tertiary } \\
\text { referrals Italy }\end{array}$ & & $\begin{array}{l}\text { Focal onset and } \\
\text { unclassified }\end{array}$ \\
\hline Park et $a l^{21}$ & $\begin{array}{l}\text { 4-year retrospective; } \\
\text { sample size- } 63 \text { with } \\
\text { sleep seizures }\end{array}$ & $\begin{array}{l}2 \text { or more, unprovoked; } \\
\text { all had sleep-provoked } \\
\text { EEG }\end{array}$ & $\begin{array}{l}\text { Retrospective cohort of } \\
\text { outpatients; single centre } \\
\text { South Korea }\end{array}$ & $\begin{array}{l}35 \% \text { untreated at entry; } \\
\text { all patients received } \\
\text { antiepileptic drugs }\end{array}$ & $\begin{array}{l}\text { Syndromic epilepsy-for } \\
\text { example, juvenile } \\
\text { myoclonic epilepsy }\end{array}$ \\
\hline $\mathrm{D}^{\prime}$ Alessandro et $\left.a\right|^{22}$ & $\begin{array}{l}\text { Consecutive patients } \\
\text { over } 4 \text { years; sample } \\
\text { size-161 }\end{array}$ & $\begin{array}{l}2 \text { or more within } 2 \text { years; } \\
\text { must have witness }\end{array}$ & $\begin{array}{l}\text { Prospective cohort; } \\
\text { Multicentre in northeast } \\
\text { Italy }\end{array}$ & $\begin{array}{l}46 \% \text { at enrolment, } 93 \% \\
\text { at end of follow-up }\end{array}$ & Frontal-lobe epilepsy \\
\hline $\begin{array}{l}\text { Fernández and Salas- } \\
\text { Puig }^{7}\end{array}$ & $\begin{array}{l}\text { Retrospective } 10 \text { years; } \\
\text { sample size }-55 \text { with } \\
\text { sleep seizures }\end{array}$ & $\begin{array}{l}3 \text { or more seizures; no } \\
\text { awake seizures for } \\
10 \text { years }\end{array}$ & $\begin{array}{l}\text { Retrospective cohort of } \\
\text { outpatients; single } \\
\text { University Hospital } \\
\text { centre, Spain }\end{array}$ & $\begin{array}{l}2 \text { untreated } \\
64 \% \text { monotherapy, } 31 \% \\
\text { dual therapy } \\
1 \text { on three antiepileptic } \\
\text { drugs }\end{array}$ & $\begin{array}{l}\text { Under } 18 \text { s; absences and } \\
\text { myoclonus }\end{array}$ \\
\hline
\end{tabular}

freedom at 2 years. Park et al's study ${ }^{21}$ also confirmed a favourable response to treatment: a third were AED-naïve at entry to the study, all went on to receive medication, and 57\% were seizure-free at 2 years. Provini et $a^{\prime} s^{25}$ study was likely to include a skewed sample from the ascertainment method, who were untreated for the period of testing and certainly not treated with modern AEDs due to the length of recruitment.

\section{DISCUSSION}

\section{Context}

Early observers who have attempted to categorise seizure semiologies identified the importance of sleep on epilepsy. Gowers recognised that some people with epilepsy had their own rhythm or pattern, some having predominantly seizures from sleep. ${ }^{26}$ His study of 840 people with epilepsy stated that $21 \%$ had seizures 'only or almost only at night.' On discussing the periodicity of attacks he said 'Frequently fits which have recurred for a time in one condition, during sleep, waking or both, change their time,' recognising that some sleep-related epilepsy could transform into awake seizures. Studies by both Langdon-Down and Brain $^{27}$ (66 institutionalised patients) and Hopkins ${ }^{2}$ (302 people with epilepsy, including first seizures and people of normal IQ) identified that people with sleep-related epilepsy were at risk of later developing awake seizures.

\section{Late risk of transformation}

In Fernandez and Salas-Puig's ${ }^{7}$ paper, the 17 who developed new awake seizures were not excluded from later analysis, and so we know that three had more than 10 awake seizures in 10 years, and four only had single seizures while awake. Of note, the majority of these were focal (skewed perhaps by the over representation of partial onset seizures). Most people who had awake seizures were also on two or more AEDs: the authors suggested that this may represent a more drug-resistant epilepsy. As 10/17 of the awake seizures occurred during drug withdrawal, nonconcordance with prescribed medication also must be considered.

Only $3 \%$ of their study group had generalised seizures $(38 \%$ undetermined). Did very few people with generalised-onset pure sleep-related epilepsy manage the 10 years without awake seizures, to enable them to be included in the paper? Or perhaps people with generalised-onset seizures achieved total seizure freedom and the partial-onset group represent a subset with relative AED resistance who continued to have sleep seizures.

\section{Accident risk}

It is possible to understand why the present UK rule recommending a 3-year observation period before granting a 3-year licence on review was unchanged after looking at the 2-year risk from Gibberd and Bateson's paper ${ }^{3}$ of $15 \%$ (95\% CI (8.2 to $26.5 \%)$ ) (figure 2). However, as stated above, the management of pure sleep-related epilepsy has changed in the 30 years following the landmark paper, particularly with regards to treatment. D'Alessandro et al's study "22 "figure 3" has a maximum estimated chance of seizure while driving in the next year of $5.7 \% 95 \% \mathrm{CI}$ (3.0 to 10.4\%). This is comparable with the difference in accident rate attributable to the day of the week (Sunday vs Tuesday) or the month (July vs April). It is important to recognise a weakness when comparing these calculated risks: some papers enrolled
Figure 2 Probability of new awake seizures, from Gibberd and Bateson. ${ }^{3}$ High transformation rates relate to low likelihood of treatment with antiepileptic drugs, and also patients were removed from study if they became seizure-free

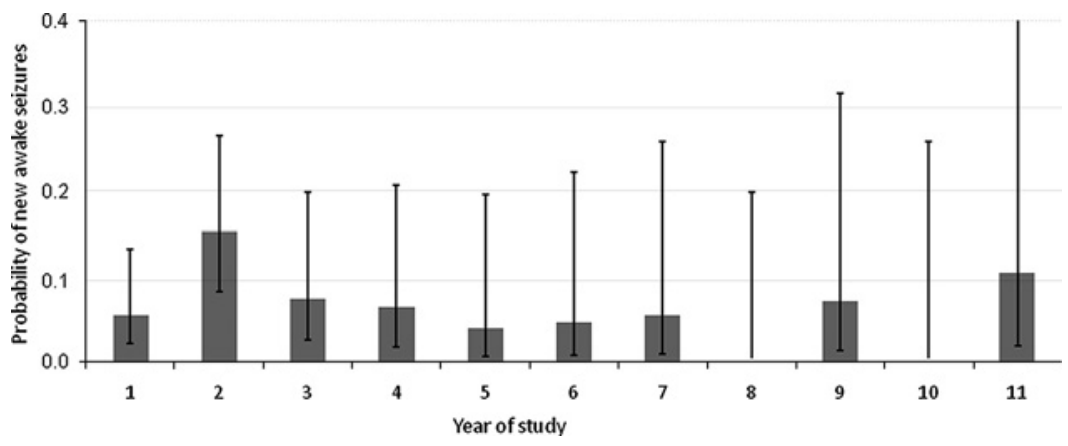




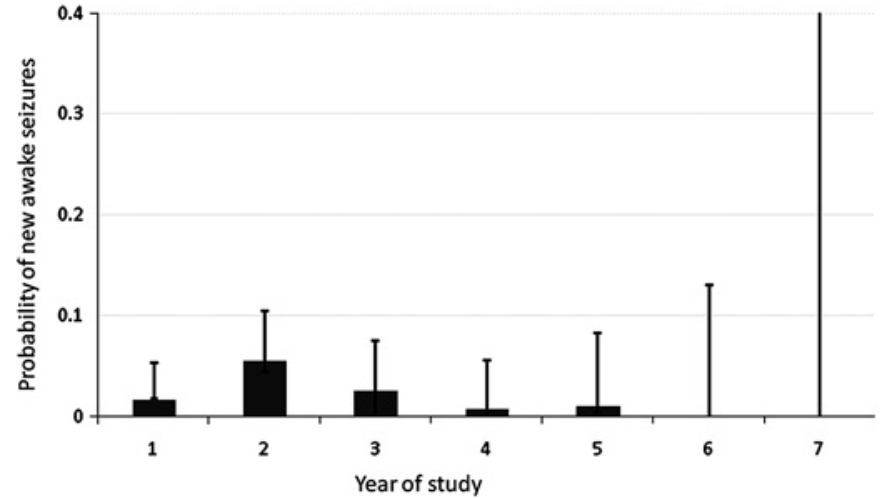

Figure 3 Probability of new awake seizures from D'Alessandro et al. ${ }^{20}$ Risk of transformation considerably below the 0.2 level $(20 \%$ chance of seizure in the next year) mark. The study excluded nocturnal frontal-lobe epilepsy, however.

patients with a new diagnosis (time to new awake seizure represents time in the study not necessarily time from first seizure or first diagnosis); ${ }^{22}$ some papers recruited patients with the diagnosis regardless of time from first seizure, and in some cases this was many years. ${ }^{3} 721$

An individual's relative risk of a fatal accident will vary depending on the number of hours spent behind the wheel and the chance of any accident being a fatal one. A cautious, lowspeed driver of a modern vehicle in a rural area will be at a lower risk than a speeding, truck driver, without a seat-belt, driving though a heavily built up area. Reflecting this scenario, presently a risk of a seizure at the wheel in the next year of $2 \%$ is recommended for Group 2 licences. Group 2 drivers (eg, lorry drivers) may spend five times longer behind the wheel, and accidents may be three times more likely to be fatal, equating to a 15-fold increase in risk. However, it is predicted therefore that the acceptable risk would vary between and within countries.

\section{Variation in the definition of pure sleep-related epilepsy}

The ambiguity inherent in the ILAE definition of 'sleep epilepsy' has led authors to coin the term 'pure sleep epilepsy;' whether a driver with greater than $90 \%$ of their seizures during sleep would be safe to drive depends entirely on seizure frequency. However, it is clear that there is little agreement as to the optimum definition of pure sleep-related epilepsy for use in the studies included in our analysis, or to assist driving regulations. This is of importance for two main reasons. First, overly rigid operational criteria mean that a great deal of probable sleeprelated epilepsy has been excluded from all the studies. If sleeprelated epilepsy possibly affects $12 \%$ of the epilepsy population, why did Park et $a l^{21}$ and D'Alessandro et al ${ }^{22}$ need 4 years each to recruit their cohorts? Second, it is important to know whether there are two identifiable groups; pure sleep-related epilepsy (never had an awake event) and sleep-related epilepsy (infrequent awake events) because they may need separate rulings when interpreting driving law.

We recommend the use of sleep-related seizures/epilepsy, as of course without overnight monitoring it would be impossible to ascertain whether all events occurred from sleep. We prefer the term awake seizures to the previously used wake seizures (to differentiate from seizures on wakening). We also would refrain from diagnosing pure sleep-related epilepsy lightly, knowing that new awake seizures can occur even after $10-20$ years. ${ }^{7}$

\section{Recommendations}

There is a paucity of data to support driving law and in particular to guide licence provision for those with pure sleeprelated epilepsy. It is important that the evidence is current, particularly as antiepileptic prescription options and patterns have changed. On the basis of a single study ${ }^{22}$ (which importantly excluded frontal-lobe epilepsy) it would appear that people who have had two or more seizures only from sleep can be granted driving licences: their additional risk of a fatal accident is not greater than other legal road users. It would appear sensible for them to observe the usual seizure ineligibility period prior to returning to driving as per current UK regulations; this is presently a year.

It would be predicted that in those with pure sleep-related epilepsy who are unmedicated, withdrawing medication or being likely to self-discontinue treatment would present an unacceptable risk of an awake seizure. Additionally, care should be taken when offering a licence to a patient with a high seizure frequency prior to medication, until further evidence can answer this uncertainty.

As awake seizures are relatively rare in people with hitherto pure sleep-related epilepsy, larger more comprehensive prospective studies are needed. Not only will these inform the legal aspects of driving, but, equally importantly for clinicians, they will enable evidence-based communication and treatment decisions. A number of treatment uncertainties remain, including: whether we really need to treat pure sleep-related epilepsy; how long to treat patients with pure sleep-related epilepsy; whether it is ever reasonable to consider withdrawing medications; whether treating pure sleep-related epilepsy reduces the risk of sudden death in epilepsy; and whether the present risk mode ${ }^{13}$ correctly estimates the fatal accident risk for people with epilepsy. ${ }^{28}$ Crucially, we wait to discover whether treated focal-onset epilepsy is associated with an unacceptable risk of awake seizures.

\section{CONCLUSION}

One hundred and twenty-eight years on from Gowers, ${ }^{26}$ we still do not know the natural history of sleep-related epilepsy, and in particular treated sleep-related epilepsy. It is likely that its response to antiepileptic treatment is favourable and that new awake seizures are associated with medication withdrawal. However, there is a dearth of comprehensive prospective data on which to base decisions regarding driving law. We may be penalising people without increased risk of awake seizures, while failing to identify subgroups at unacceptable risk of an awake seizure at the wheel.

Acknowledgements We are grateful for the views of the DVLA (Secretary of State's Panel on Driving and Disorders of the Nervous System) to whom these data were presented in March 2009. We wish to acknowledge the work of E Schmedding, who presented his risk model to the Panel in 2007, and it is on the basis of this work that many decisions across the Medical Panels are made. We are grateful to T Marson for his detailed and constructive comments when reviewing this paper for the Journal. Many thanks to the Whitchurch Hospital Library staff for their support in sourcing papers necessary for this review. We are indebted to the authors who entered into correspondence with us and provided access to their original data where available: SA Park and B-I Lee; R D'Alessandro and L Bassein; J Salas-Puig and LB Fernandez.

Competing interests PEMS has been a member of the Secretary of State's Panel on Driving and Disorders of the Nervous System since October 2004.

Provenance and peer review Not commissioned; externally peer reviewed.

\section{REFERENCES}

1. http://www.shaktitechnology.com/hippocrat.htm Author Hippocrates, translated by Francis Adams. The internet classics archive. accessed 6 April 2009. 
2. Hopkins $\mathbf{H}$. The time of appearance of epileptic seizures in relation to age, duration and type of the syndrome. J Nerv Ment Dis 1933;7:153-62.

3. Gibberd FB, Bateson MC. Sleep epilepsy: its pattern and prognosis. BMJ 1974:2:403-5

4. Janz D. The grand mal epilepsies and the sleeping-waking cycle. Epilepsia 1962:3:69-109

5. Goel D, Mittal M, Bansal KK, et al. Sleep seizures versus wake seizures: a comparative hospital study on clinical, electroencephalographic and radiological profile. Neurol India 2008:56:151-5.

6. Panayiotopoulos CP, Michael M, Sanders S, et al. Benign childhood focal epilepsies: assessment of established and newly recognized syndromes. Brain 2008:131:2264-86.

7. Fernández LB, Salas-Puig J. Pure sleep seizures: risk of seizures while awake. Epileptic Disord 2007:9:65-70.

8. Yaqub BA, Waheed G, Kabiraj MM. Nocturnal epilepsy in adults. Seizure 1997:6:145-9

9. Johnston A, Smith P. Sudden unexpected death in epilepsy. Expert Rev Neurother 2007:7:1751-61.

10. http://www.dft.gov.uk/pgr/statistics/datablepublications/vehicles. accessed 21 December 2009). Author - Transport Statistics Great Britain for the Department of Transport (UK) published online 26 November, 2009.

11. http://www.dvla.gov.uk/medical/ataglance.aspx. accessed 6 April 2009.

12. Thomas RH, Hughes TAT. Can I drive? LEAN thinking may help us answer the question. Pract Neurol 2009;9:71-8.

13. Schmedding $\mathbf{E}$, Belgian Working Group on Epilepsy and Driving. Epilepsy and driving in Belgium: proposals and justification. Acta Neurol Belg 2004;104:68-79.

14. Beghi E, Sander JS. Epilepsy and driving. BMJ 2005;331:60-1.

15. Driving regulations Task Force. International Bureau for Epilepsy. http://www. ibe-epilepsy.org/activities/epilepsy-and-driving. accessed 13 July 2009.
16. Institute for European traffic law. http://www.eu-traffic-law.org. accessed 13 July 2009.

17. Inoue $\mathbf{Y}$, Ito $\mathrm{M}$, Kurihara $\mathrm{M}$, et al. Epilepsy and driving in Japan. Epilepsia 2004:45:1630-5

18. Krauss GL, Ampaw L, Krumholz A. Individual state driving restrictions for people with epilepsy in the US. Neurology 2001; 57:1780-5.

19. Beran RG, Devereux JA. Road not taken: lessons to be learned from Queen v. Gillett. Intern Med J 2007;37:336-9.

20. D'Alessandro R, Sintini M, Pazzaglia P. et al. Pure sleep epilepsies: prognostic features. In: Epilepsy: an update on research and therapy. Edited by Giuseppe Nistico, Raoul Di Perri and H Meinardi, New York: Alan R. Liss, 1983:235-9.

21. Park SA, Lee BI, Park SC, et al. Clinical courses of pure sleep epilepsies. Seizure 1998:7:369-77.

22. D'Alessandro R, Guarino M, Greco G, et al. Risk of seizures while awake in pure sleep epilepsies: a prospective study. Neurology 2004;62:254-7.

23. Woodward M. Epidemiology: study design and data analysis. 2nd edn. Boca Raton: Chapman \& Hall/CRC, 2005:231-2.

24. Newcombe RG. Two-sided confidence intervals for the single proportion: comparison of seven methods. Stat Med 1998:17:857-72.

25. Provini $\mathbf{F}$, Plazzi $G$, Tinuper $P$, et al. Nocturnal frontal lobe epilepsy: a clinical and polygraphic overview of 100 consecutive cases. Brain 1999;122:1017-31.

26. Gowers WR. Epilepsy and other chronic convulsive diseases: their causes, symptoms, treatment. London: J.A. Churchill, 1881:197.

27. Langdon-Down M, Brain WR. Time of day in relation to convulsions in epilepsy. Lancet 1929:213:1029-32.

28. Spencer MB, Carter T, Nicholson AN. Limitations of risk analysis in the determination of medical factors in road vehicle accidents. Clin Med $2004: 4 ; 50-3$.

\section{Association of British Neurologists}

\section{1-14 May 2010 Annual Meeting}

BIC Bournemouth

Deadline for Abstract submissions: Monday 18th January 2010

Deadline for Meeting Registration: Monday 12th April 2010

Contact info@theabn.org 02074054060 